\title{
Brain invasion and the risk of seizures in patients with meningioma
}

\author{
*Katharina Hess, MD, ${ }^{1}$ Dorothee Cäcilia Spille, MD, ${ }^{2}$ Alborz Adeli, ${ }^{3}$ Peter B. Sporns, MD, ${ }^{3}$ \\ Caroline Brokinkel, MD, ${ }^{3}$ Oliver Grauer, MD, PhD, ${ }^{4}$ Christian Mawrin, MD, ${ }^{5}$ Walter Stummer, MD, ${ }^{2}$ \\ Werner Paulus, MD, ${ }^{1}$ and Benjamin Brokinkel, MD²
}

${ }^{1}$ Institute of Neuropathology and Departments of ${ }^{2}$ Neurosurgery and ${ }^{4}$ Neurology, University Hospital Münster; ${ }^{3}$ Department of Clinical Radiology, University of Münster, North Rhine-Westphalia; and ${ }^{5}$ Institute of Neuropathology, Otto-von-Guericke University, Magdeburg, Saxony-Anhalt, Germany

OBJECTIVE Identification of risk factors for perioperative epilepsy remains crucial in the care of patients with meningioma. Moreover, associations of brain invasion with clinical and radiological variables have been largely unexplored. The authors hypothesized that invasion of the cortex and subsequent increased edema facilitate seizures, and they compared radiological data and perioperative seizures in patients with brain-invasive or noninvasive meningioma.

METHODS Correlations of brain invasion with tumor and edema volumes and preoperative and postoperative seizures were analyzed in univariate and multivariate analyses.

RESULTS Totals of $108(61 \%)$ females and $68(39 \%)$ males with a median age of 60 years and harboring totals of $92(52 \%)$ grade I, $79(45 \%)$ grade II, and $5(3 \%)$ grade III tumors were included. Brain invasion was found in $38(22 \%)$ patients and was absent in $138(78 \%)$ patients. The tumors were located at the convexity in $72(41 \%)$ patients, at the falx cerebri in $26(15 \%)$, at the skull base in $69(39 \%)$, in the posterior fossa in $7(4 \%)$, and in the ventricle in $2(1 \%)$; the median tumor and edema volumes were $13.73 \mathrm{~cm}^{3}$ (range $0.81-162.22 \mathrm{~cm}^{3}$ ) and $1.38 \mathrm{~cm}^{3}$ (range $0.00-355.80 \mathrm{~cm}^{3}$ ), respectively. As expected, edema volume increased with rising tumor volume $(p<0.001)$. Brain invasion was independent of tumor volume $(p=0.176)$ but strongly correlated with edema volume $(p<0.001)$. The mean edema volume in noninvasive tumors was $33.0 \mathrm{~cm}^{3}$, but in invasive tumors, it was $130.7 \mathrm{~cm}^{3}(p=0.008)$. The frequency of preoperative seizures was independent of the patients' age, sex, and tumor location; however, the frequency was $32 \%(n=12)$ in patients with invasive meningioma and $15 \%(n=21)$ in those with noninvasive meningioma $(p=0.033)$. In contrast, the probability of detecting brain invasion microscopically was increased more than 2-fold in patients with a history of preoperative seizures (OR 2.57, 95\% Cl 1.13-5.88; $p=0.025)$. In univariate analyses, the rate of preoperative seizures correlated slightly with tumor volume $(p=0.049)$ but strongly with edema volume $(p=0.014)$, whereas seizure semiology was found to be independent of brain invasion $(p=0.211)$. In multivariate analyses adjusted for age, sex, tumor location, tumor and edema volumes, and WHO grade, rising tumor volume (OR 1.02, 95\% Cl 1.00-1.03; $p=0.042$ ) and especially brain invasion (OR 5.26, 95\% Cl 1.52-18.15; $p=0.009$ ) were identified as independent predictors of preoperative seizures. Nine (5\%) patients developed new seizures within a median follow-up time of 15 months after surgery. Development of postoperative epilepsy was independent of all clinical variables, including Simpson grade $(p=0.133)$, tumor location ( $p=$ $0.936)$, brain invasion $(p=0.408)$, and preoperative edema volume $(p=0.081)$, but was correlated with increasing preoperative tumor volume $(p=0.004)$. Postoperative seizure-free rates were similar among patients with invasive and those with noninvasive meningioma ( $p=0.372$ ).

CONCLUSIONS Brain invasion was identified as a new and strong predictor for preoperative, but not postoperative, seizures. Although also associated with increased peritumoral edema, seizures in patients with invasive meningioma might be facilitated substantially by cortical invasion itself. Consideration of seizures in consultations between the neurosurgeon and neuropathologist can improve the microscopic detection of brain invasion.

https://thejns.org/doi/abs/10.3171/2017.11.JNS172265

KEYWORDS brain invasion; edema; epilepsy; meningioma; seizures; oncology

ABBREVIATIONS AED = antiepileptic drug; EI = edema index; PTBE = peritumoral brain edema.

SUBMITTED September 29, 2017. ACCEPTED November 4, 2017.

INCLUDE WHEN CITING Published online April 27, 2018; DOI: 10.3171/2017.11.JNS172265.

* K.H. and D.C.S. contributed equally to this work. 
I MPROVING the prediction of perioperative seizures remains crucial in the neurosurgical and neurological care of patients with meningioma. ${ }^{4}$ Brain invasion by meningiomas is characterized by tonguelike infiltration of tumor cells into the underlying parenchyma and breakdown of the arachnoid layer. ${ }^{15,20}$ Several studies have found a subsequent strong astrocytic response and alterations of the adjacent cortex, ${ }^{7,13,17,18,24}$ and brain invasion was found to correlate with increased peritumoral brain edema (PTBE) ${ }^{11}$ both of these factors possibly affect cortical function and therefore seizure development. Moreover, a stronger adhesion with the underlying parenchyma of brain-invasive compared with noninvasive meningiomas ${ }^{16}$ has been described. Hence, intraoperative microsurgical dissection might lead to increased cortical trauma, additionally facilitating postoperative seizures. However, to our knowledge, the association of microscopic brain invasion with clinical or radiological findings has hardly been investigated, and correlations with perioperative seizures have not been investigated at all. ${ }^{1}$

Hypothesizing that higher PTBE volumes and histopathological alterations of the cortical surface in invasive tumors lead to an increased risk of epilepsy, we compared radiological findings and the incidence of perioperative seizures in a large series of brain-invasive and noninvasive meningiomas.

\section{Methods \\ Data Recovery}

Recovery of clinical and histopathological data was described in previous reports. ${ }^{2,20}$ In brief, archives of the Institute of Neuropathology in Münster, Germany, were reviewed for all patients with a histopathologically diagnosed primary meningioma who underwent resection at University Hospital Münster between 1991 and 2015. Among these patients, all those with a primary brain-invasive or atypical/anaplastic meningioma and 92 randomly selected patients with a grade I tumor were included. Patients with a history of a cranial pathology that also facilitates epilepsy (e.g., infection/inflammation, head trauma, intracranial hemorrhage, developmental anomaly) and/or patients who had undergone previous cranial surgery were excluded from our analyses. Baseline clinical data were obtained from medical and operative reports and included age at diagnosis, sex, and extent of resection according to the Simpson classification system. ${ }^{19}$ History of preoperative or postoperative seizures was registered according to the standard in our institution. For subgroup analyses, preoperative seizures were classified further as generalized, focal, or partial. All patients with preoperative seizures received antiepileptic drugs (AEDs) before surgery, and continuation of them was recommended for at least 1 year after surgery. No prophylactic AEDs were administered to patients who had no preoperative seizures. Surgery was generally indicated for any space-occupying and/or symptomatic tumor inaccessible via radiosurgical treatment. After maximum safely achievable tumor resection or reduction, adjuvant irradiation was administered for primary grade III and recurrent or subtotally resected grade II tumors and for benign lesions after debulking. For this study, microscopic slices of all the tumors were reviewed. Histopathological grading and tumor subtyping were performed according to the current 2016 WHO criteria in all cases, ${ }^{15}$ and brain invasion was rated by a team of 2 neuropathologists. Brain invasion was evaluated using light microscopy on $\mathrm{H} \& \mathrm{E}$ - and elastica van Gieson-stained slides and diagnosed if "irregular, tongue-like protrusions of tumor cells infiltrating underlying parenchyma, without an intervening layer of leptomeninges" 15 were seen (as illustrated in Fig. 1C and F). Radiological imaging was analyzed by 2 radiologists blinded to clinical and histopathological data to determine tumor location (classified as being at the convexity, at the falx cerebri [parasagittal], at the skull base, in the posterior fossa, or in the ventricle) and tumor and edema volumes $\left(\mathrm{V}_{\mathrm{T}}\right.$ and $\mathrm{V}_{\mathrm{E}}$, respectively). Volumes were estimated using the following established formula for a spheroid: $\mathrm{V}=4 / 3 \times \pi \times \mathrm{r} 1 \times \mathrm{r} 2 \times \mathrm{r} 3 .^{14,21} \mathrm{In}$ this formula, $r$ indicates radius, which is $50 \%$ of the tumor diameter at the site of its largest extension in the axial (r1), coronal (r2), and sagittal (r3) planes. The relationship between the tumor and edema volumes (edema index [EI]) was calculated by the formula $\left(\mathrm{V}_{\mathrm{T}}+\mathrm{V}_{\mathrm{E}}\right) / \mathrm{V}_{\mathrm{T}}$. Hence, an EI of 1 indicates no PTBE. ${ }^{14,21}$ Data collection and scientific use were approved by the local ethics committee and allowed by the patient in each case.

\section{Statistical Analyses}

Calculations were performed using standard commercial statistical software (IBM SPSS Statistics, version 24), and data are described with standard statistics, including medians, ranges, and SDs for continuous variables and absolute and relative frequencies for categorical variables. The Fisher exact test and Mann-Whitney U-test were performed to compare categorical and continuous variables, respectively. Multivariate analyses were performed using backward Wald logistic regression and are further characterized by ORs, 95\% CIs, and Wald-test $\mathrm{p}$ values. Throughout the analyses, a $\mathrm{p}$ value of $<0.05$ was considered statistically significant. All reported $\mathrm{p}$ values are 2-sided.

\section{Results}

\section{Patient Characteristics}

Using the above-described approach, we included 108 (61\%) females and 68 (39\%) males with a median age of 60 years (range 14-86 years) harboring 38 (22\%) brain-invasive and $138(78 \%)$ noninvasive meningiomas. For these patients, histopathological analyses revealed $92(52 \%)$ grade I, $79(45 \%)$ grade II, and $5(3 \%)$ grade III tumors. Grade I tumors included 16 (17\%) transitional, 4 (4\%) secretory, 68 (74\%) meningothelial, 3 (3\%) fibrous, and 1 (1\%) angiomatous meningioma. By definition, brain invasion was absent in all patients with a grade I meningioma, but it was present in 35 (44\%) of those with an atypical and $3(60 \%)$ with an anaplastic meningioma $(\mathrm{p}<0.001)$. Of the 84 high-grade (II and III) meningiomas, 45 (54\%) were found in males and $39(46 \%)$ in females $(\mathrm{p}<0.001)$. Similarly, $22(32 \%)$ of 68 males but $16(15 \%)$ of 108 females had a brain-invasive tumor $(\mathrm{p}=0.008)$. For atypical meningiomas, grading was based solely on brain invasion 

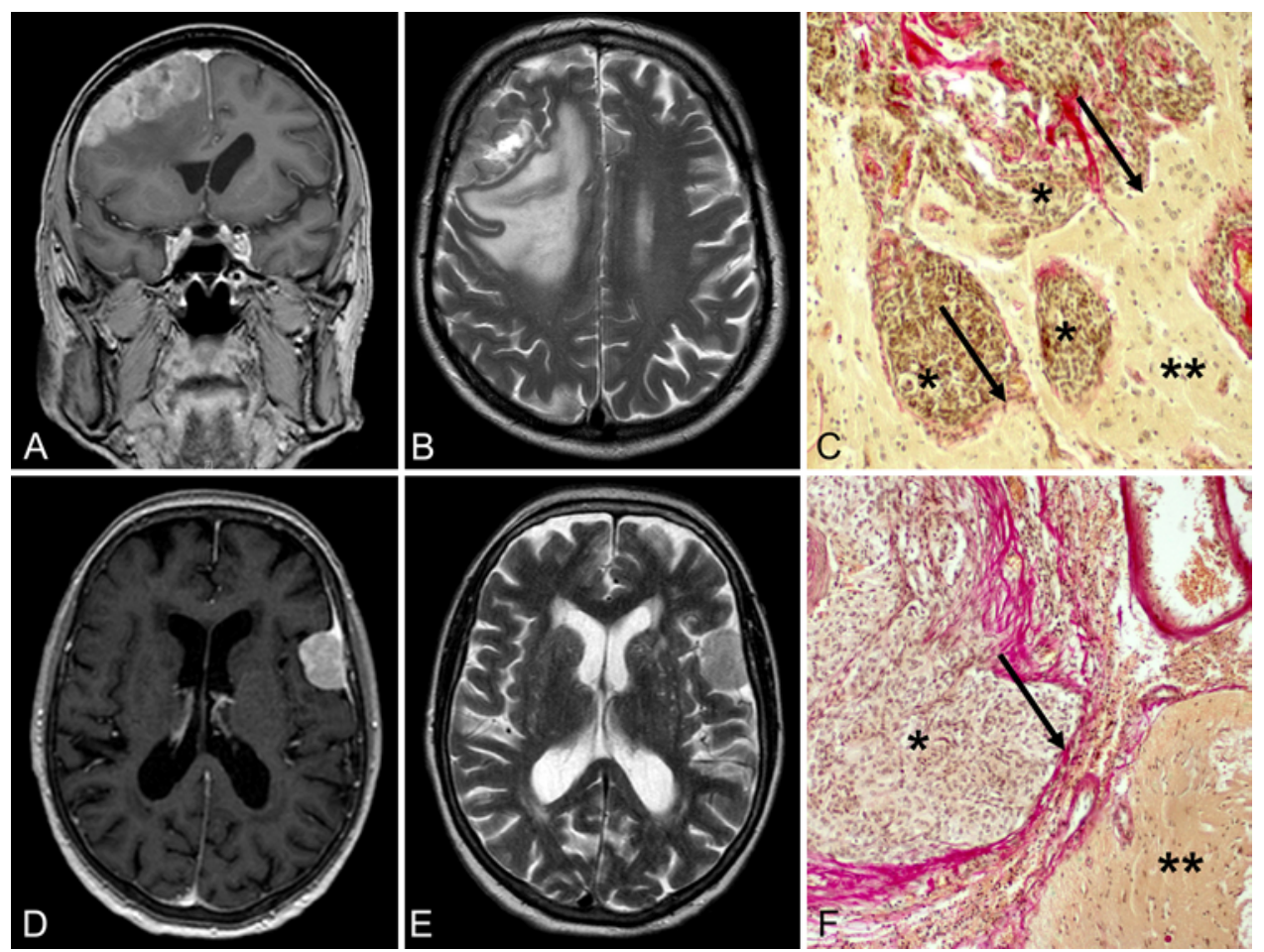

FIG. 1. Cranial MR and histopathological images of brain-invasive and noninvasive meningiomas. Coronal T1-weighted contrastenhanced (A) and axial T2-weighted (B) MR images show a large convexity meningioma with distinct PTBE in a 79-year-old male patient. Histopathological analyses $(\mathbf{C})$ (elastica van Gieson, original magnification $\times 100$ ) revealed fingerlike invasion of the tumor $\left.{ }^{*}\right)$ into the adjacent brain tissue $\left(^{* *}\right)$ with disruption of the leptomeninges (arrows, WHO grade II). Also shown are axial T1-weighted gadolinium-enhanced (D) and T2-weighted (E) MR images of a 73-year-old female. In histopathological analyses (F) (elastica van Gieson, original magnification $\times 100)$, the tumor $\left({ }^{*}\right)$ had a distinct border (arrow) to the adjacent brain tissue $\left({ }^{* *}\right)$. Figure is available in color online only.

in $22(28 \%)$ ("otherwise benign"), on other histopathological parameters in $44(56 \%)$, and on a combination of both in $13(17 \%)$. The pattern of invasion was fingerlike in 23 $(61 \%)$ of the brain-infiltrative tumor samples, clusterlike in $11(29 \%)$, and diffuse in $4(11 \%)$ (see illustrative figures in Spille et al. ${ }^{20}$ ). Meningiomas were located at the convexity in $72(41 \%)$ patients, at the falx cerebri (parasagittal) in $26(15 \%)$, at the skull base in $69(39 \%)$, in the posterior fossa in 7 (4\%), and in the ventricle in $2(1 \%)$. High-grade meningioma was diagnosed in $42(58 \%)$ of the convexity, $16(62 \%)$ of the falcine/parasagittal, $24(35 \%)$ of the skull base, and $2(100 \%)$ of the intraventricular tumors but in none of the posterior fossa tumors $(\mathrm{p}<0.001)$. Among the $172(98 \%)$ patients with available data about the extent of resection, Simpson grade I, II, III, and IV was achieved in $43(25 \%), 92$ (53\%), 22 (13\%), and 15 (9\%), respectively. No simple biopsies (Simpson grade V) were performed. Volume analysis of the preoperative tumor mass was performed for 122 (69\%) of the 176 patients with available MRI. For these patients, median tumor and edema volumes of $13.73 \mathrm{~cm}^{3}$ (range $0.81-162.22 \mathrm{~cm}^{3}$ ) and 1.38 $\mathrm{cm}^{3}$ (range $0.00-355.80 \mathrm{~cm}^{3}$ ) and a median EI of $1.05 \mathrm{~cm}^{3}$ (range 1.00-23.22 $\mathrm{cm}^{3}$ ) were calculated.

\section{Brain Invasion Correlates With Edema Volume}

In univariate analyses, brain invasion was found to be independent of tumor volume $(\mathrm{p}=0.176)$ but strongly cor- related with edema volume and EI ( $\mathrm{p}<0.001$ each, illustrated in Fig. 1A/B and D/E and Fig. 2A/B). Correspondingly, mean $\pm \mathrm{SD}$ edema volumes were $33.0 \pm 67.7 \mathrm{~cm}^{3}$ with noninvasive meningiomas but $130.7 \pm 110.2 \mathrm{~cm}^{3}$ with invasive meningiomas $(\mathrm{p}=0.008)$, and regression analyses revealed an increasing risk of microscopic detection of brain invasion with rising edema volume (OR 1.01, 95\% CI 1.01-1.02; p < 0.001) and EI (OR 1.16, 95\% CI $1.03-1.31 ; \mathrm{p}=0.017)$. As expected, the edema volume was shown to increase with rising tumor volume (Fig. 3A-C).

\section{Risk of Preoperative Seizures Correlates With Brain Invasion}

Preoperative epilepsy was found in $33(19 \%)$ patients who presented with generalized $(n=13$ [40\%]), focal $(n=$ $12[36 \%])$, or partial $(\mathrm{n}=5[15 \%])$ seizures; the type of epilepsy could not be further determined in 3 (9\%) patients. In univariate analyses (Table 1), the frequency of preoperative seizures was similar among males and females ( $\mathrm{p}$ $=0.235)$ and was independent of patient age $(p=0.930)$, sex $(p=0.235)$, and tumor location $(p=0.415)$. However, $10(11 \%)$ of 92 patients with grade I meningioma, 23 (29\%) of 79 patients with grade II meningioma, and no patients with anaplastic meningioma presented with seizures $(\mathrm{p}=$ 0.007 ). The risk of preoperative seizures was significantly higher in patients with a grade II or III tumor than in those with a grade I tumor (OR 3.10, 95\% CI 1.37-6.97; p = 

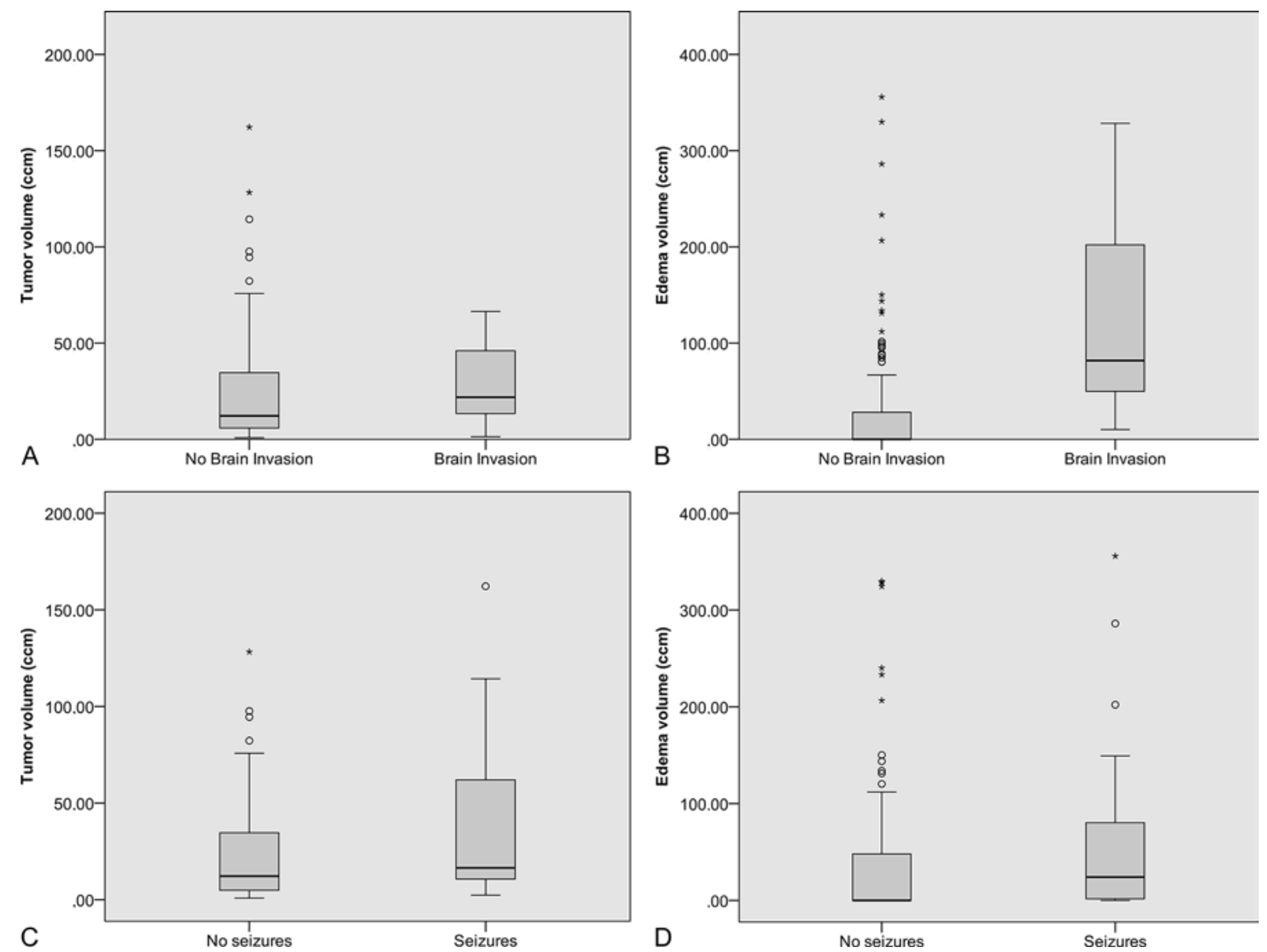

FIG. 2. Box-and-whisker plots illustrating correlations of tumor and edema volumes with brain invasion ( $\mathbf{A}$ and $\mathbf{B}$ ) and preoperative seizures $(C$ and $D)$. In univariate analyses, tumor volume was independent of brain invasion $(A, p=0.176)$ and only slightly correlated with an increased incidence of preoperative seizures $(B, p=0.049)$. However, edema volume was strongly correlated with both brain invasion $(p<0.001)$ and preoperative seizures $(p=0.014)$. In multivariate analyses, the risk of preoperative seizures was independent of the edema volume $(\mathrm{OR} 1.00,95 \% \mathrm{Cl} 0.99-1.01 ; p=0.803)$ and only slightly increased with rising tumor volume (OR 1.02, 95\% Cl 1.00-1.03; $p=0.042$ ). In contrast, brain invasion was revealed as a strong predictor for preoperative epilepsy (OR 5.26, 95\% Cl 1.52-18.15; $p=0.009$ ). Boxes indicate upper and lower 25th quartiles, whiskers indicate the minimum and maximum values, dots indicate the outliers, asterisks indicate the extreme values, and the heavy horizontal line indicates the median. $\mathrm{ccm}=$ cubic centimeter.

0.007). In grade I meningiomas, histopathological subtype correlated significantly with the rate of preoperative epilepsy $(p=0.021)$. Moreover, 12 of 38 patients with braininvasive but 21 of 117 patients with noninvasive meningioma had presented with preoperative seizures (32\% vs $18 \%$, respectively; $p=0.033$ ) (Fig. 4 left 2 bars). In contrast, the risk of microscopically detected brain invasion was distinctly increased in patients with a history of preoperative seizures (OR 2.57, 95\% CI 1.13-5.88; $p=0.025$ ). In the analysis of radiological data, we found that the incidence of preoperative seizures was correlated slightly with tumor volume ( $p=0.049)$ (Fig. 2C) but strongly with edema volume $(p=0.014)($ Fig. $2 \mathrm{D})$ and EI $(p<0.001)$. In contrast, seizure semiology was found to be independent of the presence or absence of brain invasion $(p=0.211)$.

Multivariate analyses that included age, sex, tumor location, tumor and edema volumes, WHO grade, and brain invasion were performed to identify independent predictors for preoperative seizures. Among the included variables, the incidence of preoperative seizures was indepen- dent of edema (OR 1.00,95\% CI 0.99-1.01; $\mathrm{p}=0.803$ ) and slightly increased with rising tumor volume (OR 1.02, $95 \%$ CI 1.00-1.03; $p=0.042$ ). However, the risk of seizures was increased distinctly in patients with brain-invasive meningioma over those with noninvasive meningioma (OR 5.26, 95\% CI 1.52-18.15; $\mathrm{p}=0.009$ ).

\section{Risk of Postoperative Seizures}

Within a median \pm SD follow-up period of $15 \pm 49.7$ months, $9(5 \%)$ patients experienced new postoperative seizures. No correlation was found between the frequency of new postoperative epilepsy and patient age $(p=0.299)$ or sex $(p=0.310)$, Simpson grade $(p=0.133)$, tumor location $(p=0.936)$, preoperative edema volume $(p=0.081)$, EI ( $p=0.160)$, extent of resection $(p=0.133)$, or brain invasion ( $\mathrm{p}=0.408)$ (Fig. 4, middle 2 bars). However, the incidence of postoperative seizures was positively correlated with increasing preoperative tumor volume $(p=0.004)$. Because of the low number of patients with new postoperative seizures, no multivariate analyses were performed. 

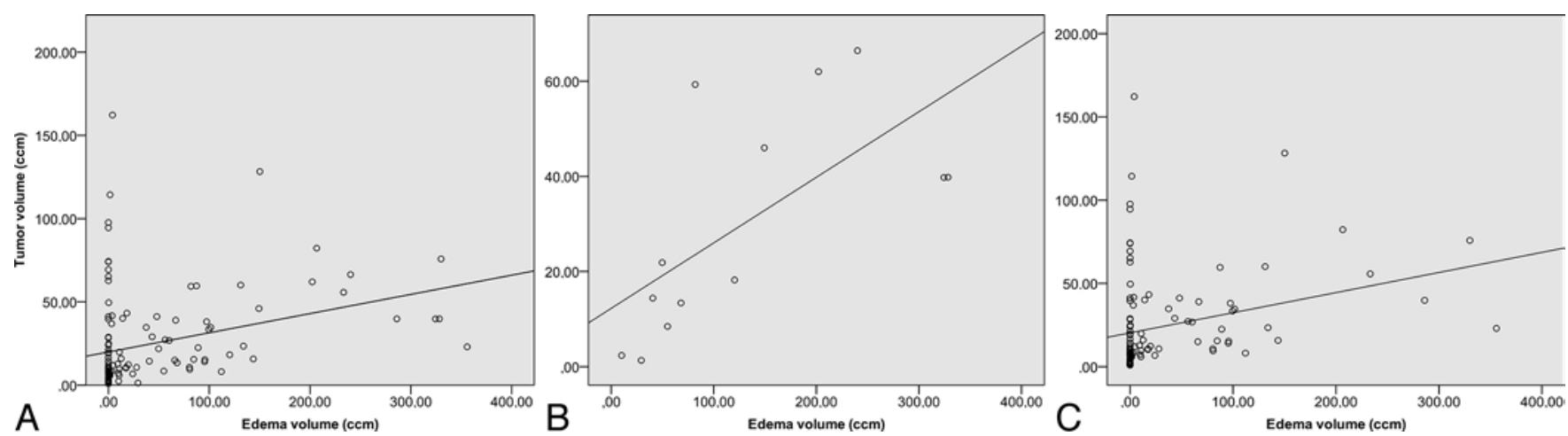

FIG. 3. Scatter plots showing the association of tumor and edema volumes (with best-fit straight line). As expected, edema volume generally increased with rising tumor volume $\left(p<0.001, R^{2}=1.01\right)(A)$. Similarly, the correlation of edema and tumor volumes was confirmed when invasive $\left(p=0.015, R^{2}=0.43\right)(B)$ and noninvasive $\left(p=0.003, R^{2}=0.08\right)(C)$ meningiomas were analyzed separately.

TABLE 1. Correlation between clinical, radiological, and histopathological variables and preoperative seizures

\begin{tabular}{|c|c|c|c|c|}
\hline \multirow[b]{2}{*}{ Variable } & \multicolumn{2}{|c|}{ Univariate Analyses } & \multicolumn{2}{|c|}{ Multivariate Analyses } \\
\hline & Seizures (\% [no.]) & $p$ Value & OR $(95 \% \mathrm{Cl})$ & $p$ Value* \\
\hline \multicolumn{5}{|l|}{ Patient characteristics } \\
\hline Age & NA & 0.930 & $1.03(0.99-1.07)$ & 0.180 \\
\hline \multicolumn{5}{|l|}{ Sex } \\
\hline Male & $24(16)$ & \multirow{2}{*}{0.235} & $1.03(0.34-3.13)$ & 0.960 \\
\hline Female & $16(17)$ & & \multicolumn{2}{|c|}{ Reference } \\
\hline \multicolumn{5}{|l|}{ Location } \\
\hline Convexity & $24(17)$ & \multirow{5}{*}{0.415} & \multicolumn{2}{|c|}{ Reference } \\
\hline Falx cerebri (parasagittal) & $23(6)$ & & $1.14(0.26-5.07)$ & 0.865 \\
\hline Skull base & $15(10)$ & & $0.50(0.15-1.70)$ & 0.269 \\
\hline Posterior fossa & $0(0)$ & & & \\
\hline Ventricle & $0(0)$ & & & \\
\hline \multicolumn{5}{|l|}{ WHO grade } \\
\hline I & $11(10)$ & \multirow{3}{*}{$0.007 \dagger$} & \multicolumn{2}{|c|}{ Reference } \\
\hline II & $29(23)$ & & $1.37(0.37-5.05)$ & 0.633 \\
\hline III & $0(0)$ & & & \\
\hline \multicolumn{3}{|l|}{ Histopathological subtype } & & \\
\hline Transitional & $25(4)$ & \multirow{5}{*}{$0.021 \dagger$} & & \\
\hline Fibrous & $0(0)$ & & & \\
\hline Meningothelial & $6(4)$ & & & \\
\hline Secretory & $50(2)$ & & & \\
\hline Angiomatous & $0(0)$ & & & \\
\hline \multicolumn{5}{|l|}{ Brain invasion } \\
\hline Present & $32(12)$ & \multirow{2}{*}{$0.033 \dagger$} & $5.26(1.52-18.15)$ & $0.009 \dagger$ \\
\hline Absent & $15(21)$ & & \multicolumn{2}{|c|}{ Reference } \\
\hline \multicolumn{5}{|l|}{ Radiological data } \\
\hline Tumor volume & NA & $0.049 \dagger$ & $1.02(1.00-1.03)$ & $0.042 \dagger$ \\
\hline Edema volume & NA & $0.014 \dagger$ & $1.00(0.99-1.01)$ & 0.803 \\
\hline El & NA & $0.002 \dagger$ & \multicolumn{2}{|c|}{ NA } \\
\hline
\end{tabular}

$\mathrm{NA}=$ not applicable (because of the small number of events/patients).

In univariate analyses, the incidence of seizures was independent of all included clinical variables but correlated with WHO grade, histopathological subtype, brain invasion, tumor and edema volumes, and El. Multivariate analyses revealed brain invasion to be the strongest predictor of preoperative seizures.

* Backward Wald regression analyses.

$\dagger$ Significant result. 


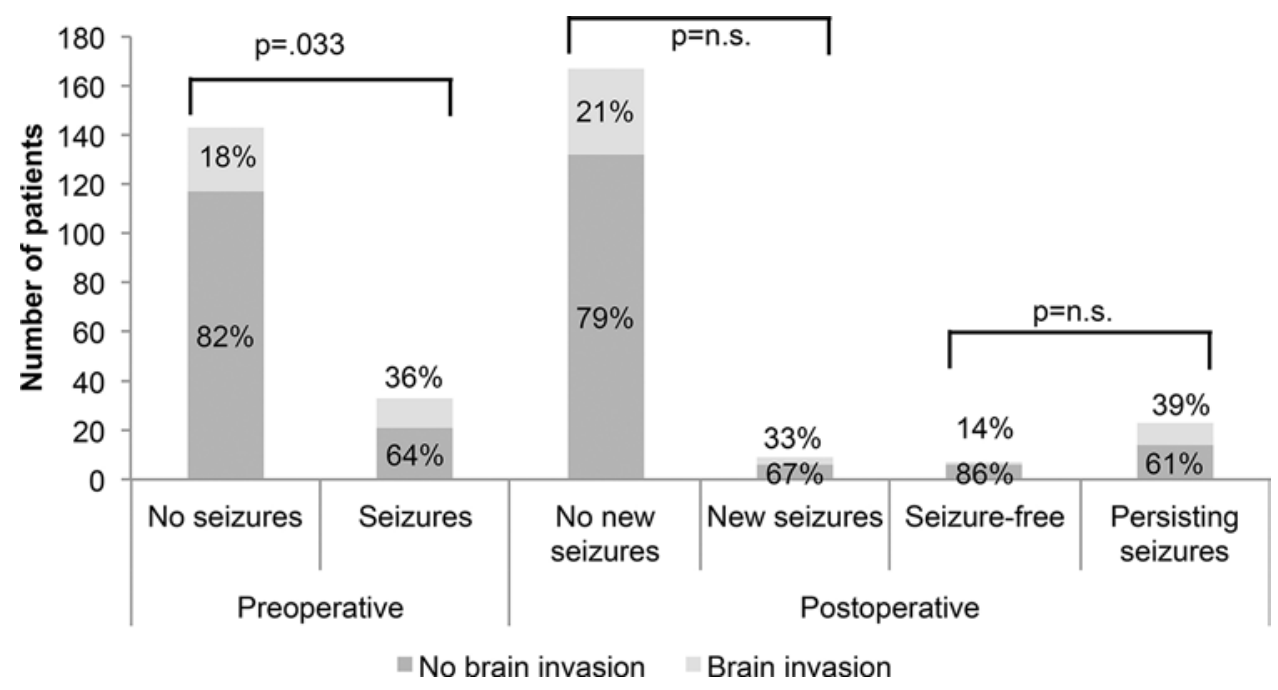

FIG. 4. Bar graphs showing the frequency of seizures in correlation with brain invasion. Brain invasion was detected in $36 \%$ of patients with preoperative seizures compared with $18 \%$ of those without preoperative seizures $(p=0.033)$. However, brain invasion was independent of the development of new postoperative seizures $(p=0.408)$ or persistence of preoperative seizures $(p=0.372)$. n.s. $=$ not significant.

Of the 33 patients with preoperative seizures, follow-up data were available for 30 (91\%), and, of these patients, 23 (77\%) were seizure free at the last follow-up visit. Among these 23 patients, 15 continued to take AEDs, including levetiracetam $(n=8)$, oxcarbazepine $(n=1)$, levetiracetam plus oxcarbazepine $(\mathrm{n}=1)$, levetiracetam plus clobazam $(\mathrm{n}=2)$, levetiracetam plus lacosamide $(\mathrm{n}=1)$, phenytoin $(\mathrm{n}=1)$ and lamotrigine $(\mathrm{n}=1)$; AED use by 2 patients could not be further specified. Histopathological analyses revealed brain invasion in $6(40 \%)$ of these 15 patients. In the remaining 8 patients, AEDs were stopped successfully without the onset of new seizures. Of 7 patients with persistent postoperative seizures, 5 continuously received AEDs (levetiracetam, $\mathrm{n}=3$; levetiracetam plus clobazam, $\mathrm{n}=1$; lamotrigine, $\mathrm{n}=1$ ), while AEDs were stopped by 2 patients for unknown reasons. In univariate analyses, 9 of 10 patients with brain-invasive meningioma and 14 of 20 patients with noninvasive meningioma experienced persistent seizures after surgery $(90 \%$ vs $70 \%$, respectively; $\mathrm{p}=$ 0.372) (Fig. 4, right 2 bars).

\section{Discussion}

With the inclusion of a grading criterion for atypia in the new WHO classification of central nervous system tumors, microscopic evidence of brain invasion in patients with meningioma has become particularly important in both clinical routine and research. ${ }^{1,10,15}$ However, although correlations between brain invasion and tumor progression are being widely investigated, data regarding the association of brain invasion with radiological findings and patient symptoms are currently sparse. ${ }^{1}$ Vranic and Gilbert ${ }^{22}$ found increased rates of behavioral changes in patients with microscopically detected brain-invasive meningioma. Moreover, Mantle et al. ${ }^{11}$ reported a strong association between brain-invasive growth and PTBE, which is one of the main risk factors for the development of perioperative seizures., ${ }^{4,612,23}$ In the same series, the authors found a
$20 \%$ increase in the incidence of brain invasion with each $1-\mathrm{cm}$ increase in edema. ${ }^{11}$ Disruption of cortical integrity by infiltrating meningioma cells with subsequent astrocytic response ${ }^{24}$ might also impair neurological function and contribute to an increased risk of seizures in patients with brain-invasive meningioma. Chernov ${ }^{5}$ reported a higher incidence of preoperative seizures in macroscopically detected brain-invasive tumors but did not assess brain invasion microscopically and did not consider both tumor and edema volumes in the analyses. Hence, for the first time (to our knowledge), we investigated correlations of brain invasion with tumor and edema volumes and the risk of perioperative seizures in a large series of patients with meningioma.

\section{Brain Invasion and the Risk of Preoperative Seizures}

Similar to Mantle et al. ${ }^{11}$ but in contrast to Pizem et al. ${ }^{16}$ we found a strong correlation of brain invasion microscopically detected with PTBE but not with tumor volume. In fact, mean edema volume was about 5-fold higher with brain-invasive tumors than with noninvasive tumors. However, although numerous histopathological alterations that accompany brain invasion were found, $7,13,17,18,24$ the expression of vascular endothelial growth factor, one of the key factors that influence PTBE, was shown to be independent of brain-invasive growth. ${ }^{1}$ Hence, the pathogenesis of distinct edema formation in brain-invasive meningiomas remains unclear.

The frequency of preoperative seizures in our study was 19\%, which is in line with the broad range of incidences reported from previous analyses., ${ }^{4,6,12,23}$ According to findings in macroscopically detected brain-invasive meningiomas, ${ }^{5}$ the incidence of preoperative seizures was distinctly higher in patients with a microscopically detected brain-invasive meningioma than in those with a noninvasive meningioma. Correspondingly, seizures were more common in patients with a high-grade than in those with a 
benign meningioma. Moreover, as expected from previous series results, $, 4,6,12,23$ rising edema and tumor volumes were positively correlated in univariate tests with an increasing incidence of preoperative seizures. However, in multivariate analyses, only increasing tumor volume (but not edema volume) remained significantly correlated with the incidence of preoperative seizures. Hence, the increased edema volume in patients with a larger meningioma might partially influence correlations of edema volume with preoperative epilepsy. It is noteworthy that we identified brain invasion to be the strongest predictor of preoperative seizures (OR 5.26; $\mathrm{p}=0.009$ ), independent of any other analyzed variable, including tumor volume (OR 1.02; $\mathrm{p}=$ 0.042 ) and edema volume (OR 1.00; $p=0.803$ ). Hence, our results suggest a crucial role of microscopically detected brain invasion itself and subsequent histopathological and neurophysiological alterations in the pathogenesis of preoperative epilepsy in patients with meningioma.

Despite a major influence on histopathological grading, and therefore on eventual adjuvant therapy and inclusion in clinical trials, neurosurgical sampling and neuropathological evaluation are not performed in a standardized manner yet but are already stipulated by clinicians and researchers. ${ }^{3,9}$ In a previous review, we proposed several considerations for improving the accuracy of detecting brain invasion in patients with meningioma, such as giving the neuropathologist information about the presence of distinct PTBE seen in preoperative MRI. In our series, the risk of finding brain invasion in meningioma specimens from patients with preoperative seizures was more than 2.5-fold higher than in those from patients without epilepsy. ${ }^{1}$ Thus, unless histopathological analyses are not performed in a standardized manner, we recommend integrating information about preoperative seizures in communications between neurosurgeons and neuropathologists to further improve the detection of brain invasion by microscopic analyses.

\section{Brain Invasion and Postoperative Seizures}

The frequency of new postoperative seizures in our series was $5 \%$ and therefore similar to that found in previously published series. ${ }^{8}$ Among all analyzed variables, only tumor volume (but not PTBE or brain invasion) was significantly correlated with the incidence of new postoperative seizures. Similarly, the proportions of postoperatively seizure-free patients did not differ on the basis of whether the patient had an invasive or noninvasive meningioma. Hence, although brain invasion by meningiomas was shown to correlate with increased intraoperative cleavability in 1 series ${ }^{16}$ our data provide no evidence that dissection of these lesions from the invaded cortex facilitates perioperative seizures. Moreover, in addition to general recommendations about the perioperative prescription of AEDs for patients with meningioma ${ }^{8}$ our results provide no rationale for considering the microscopic evidence of brain invasion in the decision making about prophylactic postoperative AEDs for patients with meningioma.

\section{Limitations of the Study}

We are aware of some limitations to our study. Because of the low frequency of brain invasion by meningiomas, a period of about 25 years was screened to obtain a sufficient number of cases for statistical analyses. Hence, our study suffers from the disadvantages of its retrospective nature and the low number of brain-invasive meningiomas limited statistical calculations in subgroup and multivariate analyses in some cases. The median follow-up period of 15 months did not allow us to make conclusions about patient prognosis in terms of either tumor progression or death. However, we aimed to assess perioperative seizures after surgery to treat meningioma, and prognostic variables were intentionally excluded from the statistical analyses. Moreover, additional parameters that specified perioperative epilepsy (such as duration or frequency of seizures) could not be obtained retrospectively.

\section{Conclusions}

We found that preoperative seizures are strongly associated with both PTBE and brain invasion. We identified microscopically detected brain invasion as a major risk factor for preoperative seizures independent of both edema and tumor volumes. On the other hand, preoperative seizures are correlated with an increased risk of brain invasion and should be included in communications between the neurosurgeon and the neuropathologist. However, the rates of postoperative development of seizures are similar in patients with brain-invasive meningioma and in those with noninvasive meningioma.

\section{References}

1. Brokinkel B, Hess K, Mawrin C: Brain invasion in meningiomas-clinical considerations and impact of neuropathological evaluation: a systematic review. Neuro Oncol 19:1298-1307, 2017

2. Brokinkel B, Holling M, Spille DC, Heß K, Sauerland C, Bleimüller C, et al: Surgery for meningioma in the elderly and long-term survival: comparison with an age- and sexmatched general population and with younger patients. J Neurosurg 126:1201-1211, 2017

3. Brokinkel B, Stummer W: Brain invasion in meningiomas: the rising importance of a uniform neuropathologic assessment after the release of the 2016 World Health Organization Classification of Central Nervous System Tumors. World Neurosurg 95:614-615, 2016

4. Chen WC, Magill ST, Englot DJ, Baal JD, Wagle S, Rick JW, et al: Factors associated with pre- and postoperative seizures in 1033 patients undergoing supratentorial meningioma resection. Neurosurgery 81:297-306, 2017

5. Chernov M: Seizures and invasive meningiomas. J Neurosurg 125:1615-1616, 2016 (Letter)

6. Englot DJ, Magill ST, Han SJ, Chang EF, Berger MS, McDermott MW: Seizures in supratentorial meningioma: a systematic review and meta-analysis. J Neurosurg 124:1552-1561, 2016

7. Fritz J, Roser F, Tatagiba M, Bornemann A: The basement membrane at the tumour-brain interface of brain-invasive grade I meningiomas. Neuropathol Appl Neurobiol 31:339342, 2005

8. Islim AI, McKeever S, Kusu-Orkar TE, Jenkinson MD: The role of prophylactic antiepileptic drugs for seizure prophylaxis in meningioma surgery: a systematic review. J Clin Neurosci 43:47-53, 2017

9. Jenkinson MD, Santarius T, Zadeh G, Aldape KD: Atypical meningioma-is it time to standardize surgical sampling techniques? Neuro Oncol 19:453-454, 2017 
10. Louis DN, Perry A, Reifenberger G, von Deimling A, Figarella-Branger D, Cavenee WK, et al: The 2016 World Health Organization Classification of Tumors of the Central Nervous System: a summary. Acta Neuropathol 131:803-820, 2016

11. Mantle RE, Lach B, Delgado MR, Baeesa S, Bélanger G: Predicting the probability of meningioma recurrence based on the quantity of peritumoral brain edema on computerized tomography scanning. J Neurosurg 91:375-383, 1999

12. Mohme M, Emami P, Regelsberger J, Matschke J, Lamszus $\mathrm{K}$, Westphal M, et al: Secretory meningiomas: increased prevalence of seizures secondary to edema formation in a rare histologic subtype. World Neurosurg 92:418-425, 2016

13. Nakasu S, Hirano A, Llena JF, Shimura T, Handa J: Interface between the meningioma and the brain. Surg Neurol 32:206-212, 1989

14. Osawa T, Tosaka M, Nagaishi M, Yoshimoto Y: Factors affecting peritumoral brain edema in meningioma: special histological subtypes with prominently extensive edema. J Neurooncol 111:49-57, 2013

15. Perry A, Louis DN, von Deimling A, Sahm F, Rushing EJ, Mawrin C, et al: Meningiomas, in Louis DN, Ohgaki H, Wiestler OD, Cavenee WK, Ellison DW, Figarella-Branger D, et al (eds): WHO Classification of Tumors of the Central Nervous System. Lyon: International Agency on Cancer Research, 2016, pp 232-245

16. Pizem J, Velnar T, Prestor B, Mlakar J, Popovic M: Brain invasion assessability in meningiomas is related to meningioma size and grade, and can be improved by extensive sampling of the surgically removed meningioma specimen. Clin Neuropathol 33:354-363, 2014

17. Rempel SA, Schwechheimer K, Davis RL, Cavenee WK, Rosenblum ML: Loss of heterozygosity for loci on chromosome 10 is associated with morphologically malignant meningioma progression. Cancer Res 53 (10 Suppl):2386-2392, 1993

18. Schittenhelm J, Mittelbronn M, Roser F, Tatagiba M, Mawrin C, Bornemann A: Patterns of SPARC expression and basement membrane intactness at the tumour-brain border of invasive meningiomas. Neuropathol Appl Neurobiol 32:525-531, 2006

19. Simpson D: The recurrence of intracranial meningiomas after surgical treatment. J Neurol Neurosurg Psychiatry 20:22-39, 1957
20. Spille DC, Heß K, Sauerland C, Sanai N, Stummer W, Paulus $\mathrm{W}$, et al: Brain invasion in meningiomas: Incidence and correlations with clinical variables and prognosis. World Neurosurg 93:346-354, 2016

21. Tamiya T, Ono Y, Matsumoto K, Ohmoto T: Peritumoral brain edema in intracranial meningiomas: effects of radiological and histological factors. Neurosurgery 49:1046-1052, 2001

22. Vranic A, Gilbert F: Prognostic implication of preoperative behavior changes in patients with primary high-grade meningiomas. Sci World J 2014:398295, 2014

23. Xue H, Sveinsson O, Tomson T, Mathiesen T: Intracranial meningiomas and seizures: a review of the literature. Acta Neurochir (Wien) 157:1541-1548, 2015

24. Zeltner L, Schittenhelm J, Mittelbronn M, Roser F, Tatagiba $\mathrm{M}$, Mawrin C, et al: The astrocytic response towards invasive meningiomas. Neuropathol Appl Neurobiol 33:163-168, 2007

\section{Disclosures}

The authors report no conflict of interest concerning the materials or methods used in this study or the findings specified in this paper.

\section{Author Contributions}

Conception and design: B Brokinkel. Acquisition of data: Hess, Spille, Adeli, Sporns, Grauer, Paulus. Analysis and interpretation of data: B Brokinkel, Hess, Adeli. Drafting the article: B Brokinkel. Critically revising the article: B Brokinkel, Hess, Mawrin, Spille, Sporns. Reviewed submitted version of manuscript: B Brokinkel, Hess, Spille, Adeli, Sporns, C Brokinkel, Stummer, Paulus. Approved the final version of the manuscript on behalf of all authors: B Brokinkel. Statistical analysis: B Brokinkel. Administrative/technical/material support: Hess, Spille, Grauer. Study supervision: B Brokinkel, Grauer, Mawrin, Stummer, Paulus.

\section{Correspondence}

Benjamin Brokinkel: University Hospital Münster, Münster, Germany. benjamin.brokinkel@ukmuenster.de. 